\title{
Р.Ю. Болдырев
}

\section{РЕГИОНАЛЬНАЯ ПОЛИТИКА СОВЕТСКИХ ОККУПАЦИОННЫХ ВЛАСТЕЙ В ГЕРМАНИИ, 1945-1949: ОТ ФЕДЕРАЛИЗМА К УНИТАРИЗМУ}

\begin{abstract}
Рассматривается становление и развитие региональной политики советских оккупационных властей в Германии. Автор, основываясь на рассекреченных документах российских и германских архивов, выделяет факторы, повлиявшие на разработку региональной политики СВАГ, причины отказа от традиционного для Германии федерализма и постепенного перехода СОЗ/ГДР к унитаризму советского типа. В статье также показано завершение оформления унитарной формы государственного устройства в ГДР в 1950-е гг.

Ключевые слова: Советская оккупационная зона Германии; Советская военная администрация в Германии (СВАГ); региональная политика; федерализм; унитаризм.
\end{abstract}

Тема региональной политики советских оккупационных властей - практически неизученная и в отечественной, и в зарубежной историографии. В разных аспектах о ней упоминали в своих работах С. Кройцбергер, Я. Фойтцик, Х. Амос, Д. Бруннер [1-4], однако ни в одном из упомянутых трудов она не удостоилась отдельного внимания. Между тем политика, проводившаяся Советской военной администрацией в Германии (СВАГ) по отношению к административнотерриториальному устройству советской оккупационной зоны (СО3), представляет несомненный интерес. Источниковой базой для написания статьи послужили впервые вводимые в научный оборот документы СВАГ, референтуры по Германии НКИД/МИД СССР, Внешнеполитической комиссии ЦК ВКП(б), а также личных фондов Вильгельма Пика, Вальтера Ульбрихта и Отто Гротеволя в Федеральном архиве ФРГ.

После капитуляции Германии 8 мая 1945 г. в СО3 произошло существенное изменение состава населения восточногерманских земель. В ходе войны в эти районы хлынул широкий поток немецких беженцев и переселенцев-репатриантов, изгнанных из мест своего проживания в Восточной Европе странами-победительницами. В результате их общая доля в населении СО3 на 1949 г. составила $24,2 \%$. При этом в ряде провинций и земель процент пришлого населения был еще выше: в Мекленбурге он составлял 43,3\%, в Бранденбурге - 24,8\%, в Саксонии-Анхальт - 24,4\% [5. В1. 82]. Среди переселенцев самой значительной группой были выходцы из земель, расположенных восточнее рек Одер и Нейсе и переданных в состав Польши, - они составляли 70\%. На втором месте по численности были судетские немцы, выселенные с территории Чехословакии, - 23,4\% [Ibid. B1. 18]. Прием такого большого количества людей способствовал размыванию традиционной для Германии региональной идентичности, смешению диалектов. Кроме того, важно отметить, что большинство переселенцев были выходцами из бывших прусских провинций, не пользовавшихся никакой внутренней автономией в составе королевства Пруссия и Германской империи. Bсе это способствовало ослаблению политических устремлений населения к сохранению прежнего федеративного устройства страны.
Доставшаяся советским оккупационным властям территория была очень неоднородной в политическом и хозяйственном отношении. Южные земли СО3 (земли Саксония и Тюрингия, провинция Саксония) являлись частью большой промышленной области, протянувшейся с запада на восток Германии. Наряду с высокоразвитой промышленностью в северных, более равнинных округах этих земель имелось достаточно развитое земледелие и садоводство [6]. Северные земли (Бранденбург и Мекленбург) характеризовались преимущественным развитием земледелия, животноводства и рыболовства [7]. Берлин со времен промышленной революции XIX в. являлся важнейшим центром обрабатывающей промышленности и крупнейшим транспортным узлом Германии - здесь перекрещивались железные и автомобильные дороги, а также водные пути, связывающие между собой разные части страны [8]. Не отличалась единством СО3 и в административнотерриториальном отношении. Ее основу составили пять провинций и земель, основанных на месте четырех бывших прусских провинций (Померания, Бранденбург, Саксония и Силезия) и трех бывших земель (Мекленбург, Тюрингия и Саксония), имевших разную историческую судьбу и правовой статус [9. В1. 74]. Земли юридически являлись правопреемницами свободных государств в составе Веймарской республики и наделялись полномочиями субъектов федерации (свои правительство, земельный парламент - ландтаг и министрпрезидент), провинции являлись составными частями Пруссии и в правовом отношении должны были полностью подчиняться правительству последней. Однако 31 мая 1947 г. Союзный контрольный совет принимает закон «О ликвидации Пруссии», уничтоживший это административно-территориальное образование и предоставивший входившим ранее в ее состав провинциям права земель [10. S. 753]. Город Берлин (в границах 1920 г.) в соответствии с Ялтинскими соглашениями был фактически выделен из состава Советской оккупационной зоны и передан под управление четырехсторонней союзной комендатуры и подконтрольного ей магистрата Большого Берлина.

Ни советское руководство, ни германские коммунисты сначала не придали вопросу об административно- 
территориальном устройстве большого внимания. Советская система оккупационного управления была приспособлена к доставшейся в наследство от нацистского режима схеме административно-территориального деления страны на общины, районы, округа и земли. Были образованы соответствующие военные комендатуры и управления СВАГ в федеральных землях, а также органы немецкого самоуправления. Провинциальные и земельные управления, возглавляемые президентом и тремя вице-президентами, были назначены СВАГ. После выборов в ландтаги 20 октября 1946 г. были образованы провинциальные и земельные правительства во главе с министрами-президентами. Центральные управления были созданы 27 июля 1945 г. для выполнения функций в масштабах всей СО3. Они не играли роли зонального правительства, а только обеспечивали единое исполнение распоряжений СВАГ в масштабах всей зоны [9. B1. 74-77]. В результате между немецкими органами самоуправления регионального и центрального уровня установились весьма напряженные взаимоотношения.

Западные союзники в 1945-1946 гг. приступили к существенному реформированию административнотерриториального устройства своих оккупационных зон. Так, американская зона в сентябре 1945 г. была разделена на три земли - Баварию, Большой Гессен, Вюртемберг-Баден. 17 октября 1946 г. по приказу американских оккупационных властей был образован совет земель (Länderrat), являющийся не только совещательным, но и полномочным органом при военном губернаторе, в который вошли три министра-президента земель. В английской оккупационной зоне 23 октября 1946 г. все территории были реорганизованы в четыре федеральные земли - Северный Рейн-Вестфалию, Нижнюю Саксонию, Шлезвиг-Гольштейн и Гамбург. В начале 1946 г. был образован зональный совет как совещательный орган при военном губернаторе. В связи с созданием Бизонии с 1 января 1947 г. земли в английской и американской оккупационных зонах получили всю полноту власти, за исключением вопросов, «находящихся в компетенции центрального германского правительства» (до его создания эти функции выполнялись английскими и американскими оккупационными властями) [9. В1. 59, 65-66]. 30 августа 1946 г. была образована земля Рейнланд-Пфальц, в результате число входящих во французскую оккупационную зону земель возросло до четырех - Саар, Южный Баден и Южный Вюртемберг-Гогенцоллерн. Никакого центрального полномочного или совещательного органа в форме земельного совета здесь создано не было [9. В1. 70-71].

Официальная позиция Москвы по вопросу о будущем административно-территориальном устройстве Германии была сформулирована Политбюро ЦК ВКП(б) в 1946 г. в выжидательном ключе: «...Если германский народ в результате плебисцита во всей Германии выскажется за превращение Германии в федеральное государство, или в результате плебисцита в отдельных бывших немецких государствах - за отделение от Германии, то с нашей стороны, конечно, не будет возражений» [11. Л. 115]. Однако к концу лета 1946 г. политическая ситуация изменилась: в западных оккупаци- онных зонах началось обсуждение проектов будущей конституции [12. Л. 122], а в самой СО3 в сентябреоктябре должны были состояться общинные и земельные выборы, поэтому собственный проект конституции мог стать серьезным козырем для СЕПГ в предвыборной борьбе [13. S. 31].

В конце июня 1946 г. СЕПГ выпускает директиву, посвященную вопросам коммунальной политики, в которой утверждалась необходимость передачи части государственных полномочий общинам и районам. Помимо управленческих функций местное самоуправление должно было обладать правами назначения и отзыва чиновников, издания местных законов и проведения референдумов. Также планировалось ограничить права региональных и центральных властей вмешиваться в вопросы местного самоуправления, влиять на назначение служащих [14. В1. 16-18]. Города потеряли свой особый статус и права, будучи практически уравнены с сельскими территориальными общинами [15. B1. 518].

В августе 1946 г. Центральным правлением СЕПГ был подготовлен и представлен на рассмотрение в СВАГ проект конституции Германии, который в вопросе о разделении полномочий между центром и землями повторял текст Веймарской конституции 1919 г. Ознакомившись с этим проектом, Правовой департамент МИД СССР дал заключение, что это политическая акция, не рассчитанная на практическое осуществление [12. Л. 19-53, 124-127]. Поэтому СВАГ рекомендовала использовать основные положения проекта при разработке и принятии конституций земель. В декабре 1946 г. в землях СО3 принимается однотипное положение об округах, в соответствии с которым район объявлялся административно-территориальной единицей и союзом расположенных по соседству и объединенных хозяйственной деятельностью общин. Сферой компетенции районных властей были определены функции, не входящие в компетенцию общин и земель. Кроме того, они должны были заниматься вопросами охраны общественной безопасности и правопорядка (для этого учреждалась районная полиция). Представительным и исполнительным органом власти объявлялось районное собрание депутатов (Kreistag), избираемое на основе прямых, всеобщих выборов на 2 года. Районное собрание избирало районное правление (Vorstand) сроком на 1 год. Районный совет (Kreisrat) как исполнительный орган районного собрания депутатов состоял из ландрата, его заместителей и еще 6 членов, избираемых районным собранием депутатов. Ландрат объявлялся председателем районного совета, распределял обязанности среди его членов, назначал и увольнял всех районных служащих (по согласованию с районным собранием депутатов). Районный совет мог отправить в отставку ландрата и других членов районного совета [15].

Зимой 1946-1947 гг. были разработаны конституции провинций и земель СОЗ. Вокруг них развернулась ожесточенная борьба СЕПГ с буржуазными партиями Либерально-демократической партией (ЛДП) и Христианско-демократическим союзом (ХДС), выступавшими за сохранение федеративного и демократического государственного строя с четким разделением властей 
и распределением полномочий между центром и регионами [16. Л. 212-214]. СЕПГ удалось обеспечить неизменность основ земельных конституций, тексты которых были официально утверждены 20 декабря 1946 г. - в Тюрингии, 10 января 1947 г. - в СаксонииАнхальт, 16 января 1947 г. - в Мекленбурге, 6 февраля 1947 г. - в Бранденбурге и 28 февраля - в Саксонии. Все они почти полностью повторяли друг друга и устанавливали жесткую вертикаль управления: 1) ландтаг, избирающий министра-президента и утверждающий в должности министров; 2) районное собрание депутатов, избирающее районный совет во главе с ландратом; 3) городское собрание депутатов, избирающее городской совет во главе с обер-бургомистром (в городах центрального подчинения) или бургомистром (в городах районного подчинения); 4) общинное представительство, избирающее совет общины с во главе с бургомистром. Высшим органом власти земли провозглашался избираемый на всеобщих выборах на 3 года ландтаг, наделенный законодательными полномочиями, правами принятия бюджета земли, надзора за деятельностью земельного правительства, административных и судебных органов. Исполнительная власть принадлежала правительству земли, состоящему из министрапрезидента и министров. В конституциях земель указывалось, что общины и районы обладают правом самоуправления, но при этом об их самостоятельных полномочиях не говорилось ни слова [17].

Реальное отношение советских оккупационных властей к немецкому федерализму и разделению властей видно по цитате из документа УСВА земли Саксония-Анхальт: «...серьезным тормозом... является широко распространенное среди работников органов управления... старой и вредной в настоящее время “теории" о том, что местные органы управления являются органами “самоуправления”» [18. Л. 55-78]. 31 января 1947 г. на встрече с немецкой делегацией во главе с В. Пиком, О. Гротеволем и В. Ульбрихтом в Москве И.В. Сталин открыто заявил, что СССР против возрождения федерализма в Германии [19. Bl. 6].

Интерес к проекту конституции для СО3 вновь возрос после созыва в сентябре 1948 г. Парламентского совета в Западной Германии. Работа над текстом велась в лихорадочном темпе, 19 марта 1949 г. проект был рассмотрен и одобрен Народным советом, а 30 марта 1949 г. - III Немецким народным конгрессом. 17 и 27 сентября 1949 г. состоялись встречи немецкой делегации во главе с В. Пиком с членами Политбюро ЦК ВКП(б), в ходе которых обсуждались ключевые вопросы государственного строительства будущей ГДР. По итогам переговоров Политбюро ЦК ВКП(б) утвердило инструкции политическому советнику Главноначальствующего СВАГ В.С. Семенову, в которых согласилось с планом по созданию ГДР, кандидатуре президента, составу и процедуре формирования правительства, проведению выборов в Народную палату ГДР [20. Л. 17; 21. Л. 10-14], которые в тот же вечер были переданы немцам [22. В1. 103-104]. 7 октября 1949 г. проект конституции был принят в качестве закона Временной народной палатой ГДР. В нем закреплялись определенные федералистские черты: сохранялось традиционное для Германии деление на земли; верхняя палата парламента (Палата земель) формировалась из представителей ландтагов; вводился пост президента, избираемого обеими палатами парламента на совместном заседании; сохранялась культурная автономия для национальных меньшинств. В то же время в компетенцию Палаты земель входили только внесение законопроектов в Народную палату и наложение вето большинством в $2 / 3$ на принятые ею законы. Компетенция земель также была существенно ограничена, в нее вошли только частные вопросы и те отрасли права, от управления которыми отказалась центральная власть [23]. На практике федеративное устройство оказалось фикцией, так как унитария лучше соответствовала тоталитарному режиму сталинского типа, постепенно складывавшемуся в ГДР.

Завершение трансформации административнотерриториальной системы ГДР произошло уже после отмены оккупационного режима. Согласно закону «О дальнейшей демократизации построения нового общества и принципов действия государственных органов власти в землях Германской Демократической Республики» от 23 июля 1952 г. предписывалась реорганизовать районы, объединив их в 14 округов, а земельным правительствам - передать свои полномочия этим округам [24]. Главное отличие округа от земли заключалось в отсутствии у него политической автономии и права самоуправления. Он стал средним звеном управления между центральными государственными учреждениями и районами. При определении границ округов в основу были положены уже не исторические или культурные, а экономические критерии. Выбор окружных центров также был призван порвать с историческим прошлым. Последним рудиментом федеративной системы осталась Палата земель - верхняя палата парламента ГДР. В 1958 г. выборы членов Палаты земель прошли непосредственно в округах, а в декабре того же года в связи с изменением конституции верхняя палата была ликвидирована.

Таким образом, в процессе реформирования административно-территориального устройства Восточной Германии после второй мировой войны можно выделить четыре этапа: 1) реорганизация земель в соответствии с новыми границами Германии, установленными Ялтинскими и Потсдамскими соглашениями в 19451946 гг.; 2) принятие конституций земель, в которых были зафиксированы их полномочия, в декабре 1946 феврале 1947 г.; 3) закамуфлированный переход к унитаризму, связанный с началом работы Немецкой экономической комиссии и разработкой Конституции ГДР в декабре 1947 - октябре 1949 г.; 4) окончательная ликвидация федеративных основ Конституции ГДР и переход к унитарному государству в 1952-1958 гг.

Ликвидация федерализма и переход к унитаризму в СОЗ/ГДР стали следствием воздействия целого ряда факторов:

1. Постепенно воспроизводимая на территории СО3/ГДР тоталитарная модель советского государства федералистского по тексту конституции, но унитарного по своей сути. Сталинское руководство не стремилось вникнуть в исторические, культурные и экономи- 
ческие особенности восточногерманских земель, а потому не видело смысла построения федерации в мононациональной стране.

2. Соотношение политических сил в самой СО3. СВАГ и СЕПГ рассматривали передачу поста министрапрезидента земли Саксонии-Анхальт представителю ЛДП Эрхарду Хюбенеру как необходимую уступку буржуазным партиям, входящим в Национальный блок, и одновременно как крупный просчет, поскольку он оказался слишком самостоятельным и потребовалось немало усилий для замены его более удобной фигурой [9. B1. 76].

3. Международная обстановка. Начало «холодной войны», укрепление народно-демократических режимов в странах Восточной Европы и фактический раскол
Германии сделали ненужными дальнейшие уступки буржуазным партиям в политических и правовых вопросах и позволили в короткий срок произвести ревизию демократических и федералистских положений Веймарской конституции 1919 г.

Дополнительными факторами, облегчившими переход к унитаризму, стали ликвидация нацистами в 1933-1934 гг. федералистских основ, заложенных в Веймарской конституции 1919 г., и размывание региональной идентичности жителей земель СО3 в результате прибытия огромного количества беженцев и переселенцев с территорий, отошедших по итогам Второй мировой войны к Советскому Союзу, Польше и Чехословакии.

\section{ЛИТЕРАТУРА}

1. Creuzberger S. Die sowjetische Besatzungsmacht und das politische System der SBZ. Weimar u.a., 1996. 215 S.

2. Foitzik J. Sowjetische Militäradministration in Deutschland (SMAD) 1945-1949. Struktur und Funktion. Berlin, 1999. 544 S.

3. Amos H. Die Entstehung der Verfassung in der Sowjetischen Besatzungszone/DDR 1946-1949. Darstellung und Dokumentation. Worms, 2005. 536 S.

4. Brunner D. Der Schein der Souveränität. Landesregierung und Besatzungspolitik in Mecklenburg-Vorpommern 1945-1949. Köln u.a., 2006. 447 S.

5. Stiftung Archiv der Parteien und Massenorganisationen der ehemaligen DDR in Bundesarchiv (SAPMO-BArch.), NY4036/744.

6. Die regionale Struktur der sowjetischen Besatzungszone in Deutschland // Statistische Praxis. 1946. № 2, Karteiblatt.

7. Die agrarische Struktur der sowjetischen Besatzungszone // Statistische Praxis. 1947. № 1, Karteiblatt.

8. Das Landverkehrsnetz der sowjetischen Besatzungszone // Statistische Praxis. 1947. № 3, Karteiblatt.

9. SAPMO-BArch., NY4182/1084.

10. Clarke Chr. Preußen. Aufstieg und Niedergang, 1600-1947. Bonn, 2007. 896 S.

11. Российский государственный архив социально-политической истории (РГАСПИ). Ф. 17. Оп. 162. Д. 38.

12. Архив внешней политики Российской Федерации (АВПРФ). Ф. 082. Оп. 30. П. 132. Д. 52.

13. Laufer J. Die Verfassungsgebung in der SBZ 1946-1949 // Aus Politik und Zeitgeschichte. 1998. № 32-33. S. $29-41$.

14. SAPMO-BArch., NY4182/1087.

15. SAPMO-BArch., NY4182/1088.

16. АВПРФ. Ф. 082. ОП. 34. П. 152. Д. 64.

17. SAPMO-BArch., NY4182/1103.

18. ГАРФ. Ф. 7133. Оп. 1. Д. 221.

19. SAPMO-BArch., NY4036/694.

20. РГАСПИ. Ф. 17. ОП. 162. Д. 41

21. РГАСПИ. Ф. 17. ОП. 162. Д. 42

22. SAPMO-BArch., NY4036/695.

23. Gesetzblatt der DDR. 1949. S. 5-16.

24. Gesetzblatt der DDR. 1952. S. 613.

Boldyrev Roman $Y u$. Northern (Arctic) Federal University named after M.V. Lomonosov (Arkhangelsk, Russia). E-mail: r.boldyrev@narfu.ru

REGIONAL POLICY OF SOVIET MILITARY ADMINISTRATION IN GERMANY 1945-1949: FROM FEDERALISM TO UNITARIANISM

Keywords: Soviet occupation zone of Germany (SOZ); Soviet Military Administration in Germany (SMAG); regional policy; federalism; unitarianism.

Regional policy of Soviet occupation authorities in Germany remains an underexplored topic both in Russian and foreign historiography. Policy of Soviet Military Administration in Germany (SMAG) held towards administrative and territorial constitution of Soviet occupation zone of Germany (SOZ) brings an undoubted interest.

The purpose of the paper is to hold a complex analysis of regional policy held by Soviet occupational authorities, and to trace its transformation from federalism towards unitary structure. The documents from SMAG, administrative office on Germany of People's commissariat/Ministry of foreign affairs of the USSR, Foreign policy commission at the Central Committee of the Communist party of Soviet Union, and so from personal heritage of Wilhelm Pieck, Walther Ulbricht and Otto Grotewohl in the Federal Archive of Federal Republic of Germany were used.

It is possible to point out four stages in process of administrative and territorial structure reforming: 1) land reorganization based on new borders of Germany in 1945-1946; 2) adopting land constitutions in December 1945-1946; 3) camouflaged transition to unitary state structure during development of the Constitution of German Democratic Republic (GDR) in December 1947 - October 1949; 4) final elimination of grounds for federal state structure in 1952-1958.

Elimination of federalism and transition to unitarianism in SOZ/GDR took place due to numerous factors:

1. Soviet totalitarian state model reproduction, which was federal according to Constitution, but unitary de-facto. Stalin's political establishment did not see any purpose in constructing federal system in a country with single nation.

2. SMAG and Socialist Unity Party of Germany recognized appointing of Erhard Hübner from Liberal democratic party to position of minister-president in Saxony-Anhalt as a trade-off to bourgeois parties, which were included into National bloc, and as a major setback since the minister turned out to be too self-sufficient figure, and it took their time to substitute him with more loyal person.

3. The emergence of Cold war, people's democracies in Eastern Europe and de-facto split up of Germany made trade-offs to bourgeois parties in political and legislative aspects unnecessary. 
In addition to these factors, the following grounds made transition to unitary state structure into practice: elimination of federalism set Weimar Constitution of Germany in 1919 during the establishment of NSDAP state in 1933-1934, and weakening of regional identities in Soviet occupation zone due to arrival of large amounts of refugees and displaced persons.

\section{REFERENCES}

1. Creuzberger, S. (1996) Die sowjetische Besatzungsmacht und das politische System der SBZ [The Soviet occupying power and the political system of the SBZ]. Weimar: [s.n.].

2. Foitzik, J. (1999) Sowjetische Militäradministration in Deutschland (SMAD) 1945-1949. Struktur und Funktion [Soviet Military Administration in Germany (SMAD) 1945-1949. Structure and function]. Berlin: De Gruyter Akademie Forschung.

3. Amos, H. (2005) Die Entstehung der Verfassung in der Sowjetischen Besatzungszone/DDR 1946-1949. Darstellung und Dokumentation [The Formation of the Constitution in the Soviet Occupation Zone / GDR 1946-1949. Presentation and documentation]. Worms: LIT.

4. Brunner, D. (2006) Der Schein der Souveränität. Landesregierung und Besatzungspolitik in Mecklenburg-Vorpommern 1945-1949 [The appearance of sovereignty. State government and occupation policy in Mecklenburg-Vorpommern 1945-1949]. Cologne: Böhlau.

5. Foundation Archive of the Parties and Mass Organizations of the former GDR in the Federal Archives (SAPMO-BArch.). NY4036/744.

6. Anon. (1946) Die regionale Struktur der sowjetischen Besatzungszone in Deutschland [The Regional Structure of the Soviet Occupation Zone in Germany]. Statistische Praxis. 2.

7. Anon. (1947) Die agrarische Struktur der sowjetischen Besatzungszone [The Agrarian Structure of the Soviet Occupation Zone]. Statistische Praxis. 1.

8. Anon. (1947) Das Landverkehrsnetz der sowjetischen Besatzungszone [The land transport network of the Soviet occupation zone]. Statistische Praxis. 3.

9. Foundation Archive of the Parties and Mass Organizations of the former GDR in the Federal Archives (SAPMO-BArch.). NY4182/1084.

10. Clarke, Ch. (2007) Preußen. Aufstieg und Niedergang, 1600-1947 [Prussia. Rise and Decline, 1600-1947]. Bonn: Pantheon Verlag.

11. The Russian State Archive of Socio-Political History (RGASPI). Fund 17. List 162. File 38.

12. The Archive of the Foreign Policy of the Russian Federation (AVPRF). Fund 082. List 30. P. 132. File 52.

13. Laufer, J. (1998) Die Verfassungsgebung in der SBZ 1946-1949 [The Constitution in the SBZ 1946-1949]. Aus Politik und Zeitgeschichte. 32-33. pp. $29-41$.

14. Foundation Archive of the Parties and Mass Organizations of the former GDR in the Federal Archives (SAPMO-BArch.). NY4182/1087.

15. Foundation Archive of the Parties and Mass Organizations of the former GDR in the Federal Archives (SAPMO-BArch.). NY4182/1088.

16. The Archive of the Foreign Policy of the Russian Federation (AVPRF). Fund 082. List 34. P. 152. File 64.

17. Foundation Archive of the Parties and Mass Organizations of the former GDR in the Federal Archives (SAPMO-BArch.). NY4182/1103.

18. The State Archive of the Russian Federation. Fund 7133. List 1. File 221.

19. Foundation Archive of the Parties and Mass Organizations of the former GDR in the Federal Archives (SAPMO-BArch.). NY4036/694.

20. The Russian State Archive of Socio-Political History (RGASPI). Fund 17. List 162. File 41

21. The Russian State Archive of Socio-Political History (RGASPI). Fund 17. List 162. File 42

22. Foundation Archive of the Parties and Mass Organizations of the former GDR in the Federal Archives (SAPMO-BArch.). NY4036/695.

23. Gesetzblatt der DDR. (1949) pp. 5-16.

24. Gesetzblatt der DDR. (1952) pp. 613. 